\title{
الكلام الخبري في قصة قصيرة "ليلة الزفاف" لنجيب الكيلالي
}

\section{Bagus Rizqi Maulana}

Universitas Islam Negeri Sunan Ampel Surabaya

inimzgusr@gmail.com

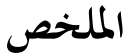

الغرض من هذا البحث هو تحديد شكل تقسيم الكلام خباري والغرض منه وجدت في قصة قصيرة بعنوان "ليلة الزفاف". كلام خباري حديث يحتوي على إمكانية الصواب والخطأ لا يُرى إلا من الحديث نفسه. هناك ثلاثة أنواع من كلام خباري ابتدائي، طلبي، وإنكاري. القصة القصيرة ليلة الزفاف من عمل نجيب الكيلائ. تدور هذه القصة القصيرة حول فتاة صغيرة تشعر بالاضطهاد عندما تتزوج من رجل عجوز. المنهج المستخدم في هذا البحث هو منهج نوعي وصفي. المنهج المستخدم في هذا البحث هو علم البلاغة. لذلك فإن البيانات التي تم إنشاؤها على شكل كلمات في شكل جمل.

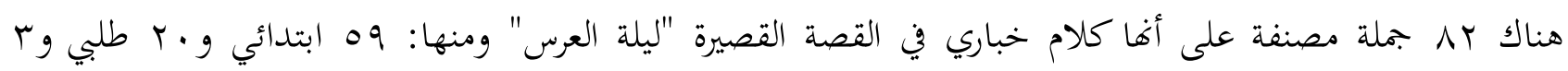
إنكاري. أما غرض كلام خباري في القصة القصيرة ليلة الزفاف ومنها: 10 فائدة الخبر، 1 لازم الفائدة.

\section{الكلمات الدالة: كلام خباري قصة قصيرة "ليلة الزفاف" نجيب الكيلاين.}

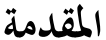

اعتبرت القصة القصيرة أحد الحكاية الأدبية النثرية في اللغة العربية، وقد انتقلت القصة القصيرة من اللغات الأوروبية إلى اللغة العربية في القرن العشرين بعد أن مرّت بالعديد من التحولات وشابها الكثير من التطوير في الشكل والبناء في القرن التاسع عشر في أوروبا خاصة على يد الفرنسي موباسان، والروسي أنطون تشيخوف، الذين لديهما كتاب وقراءة القصة القصيرة والأدب حول العالم بالكثير من الفضل. أمّا في العالم العربي فقد أدت حركة الترجمة في مطلع القرن العشرين إلى تعريف القرّاء والكتّاب العرب هذذا اللون الأدبي، ويعتبر المنفلوطي ومحمود تيمور أول من كتب القصة القصيرةالحديثةباللغةالعربية. القصة في اللغة هو اقتفاء الأثر وتتبعه، وكذلك هو الرواية والإخبار، وكلا المعنيين وطيد الصلة بالآخر، وقال الله عز وجل في القرآن الكريم عن سورة يوسف أفها أحسن القصص. نشأ مصطلح القصة القصيرة للتفريق بين ذلك اللون وبين القصة العادية، وذلك من حيث تتبع النقّاد لأهم عناصر القصة القصيرة التي يعتبر الطول أبرزه، ومع ذلك فإن القصة القصيرة يتوافر فيها كافة عناصر القصة 
الطويلة من وجود زمان، ومكان، وموضوع، مع إمكانية استغناء الكاتب عن أحدها، وتتميز عن القصة الطويلة

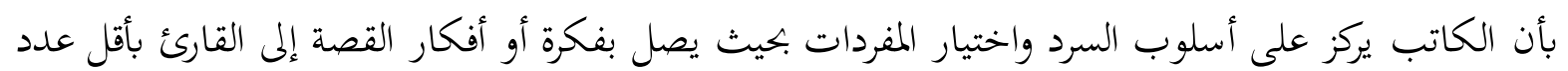

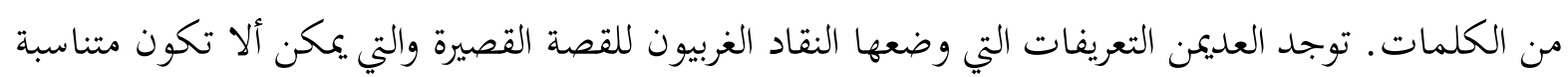

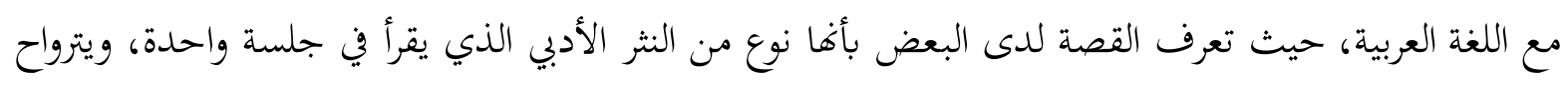

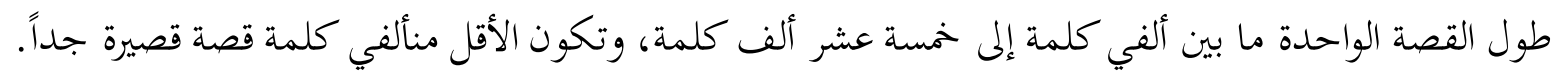

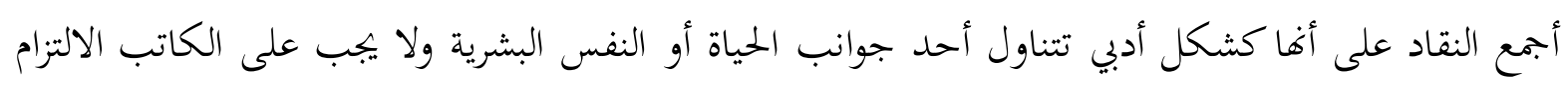

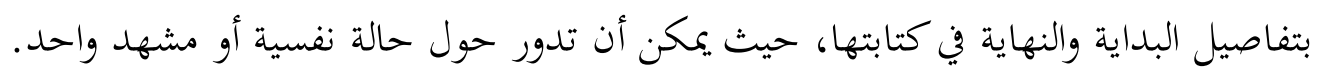
فذالك، يركز الباحث بالموضوع "الكلام الخبري في قصة قصيرة "ليلة الزفاف" لنجيب الكيلاني".

يعرض الباحث في هذا البحث منهجية البحث، فيها: مدخل البحث ونوعه وبيانات البحث ومصادرها

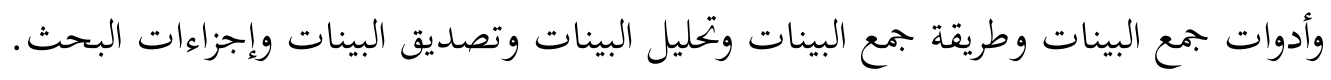

\section{مدخل البحث ونوعه}

مدخل البحث هو الطريقة لفهم المسألة حتى يستطيع أن يجد الباحث الجواب منها باستخدام الطريقة

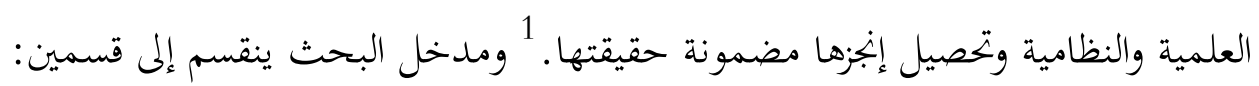

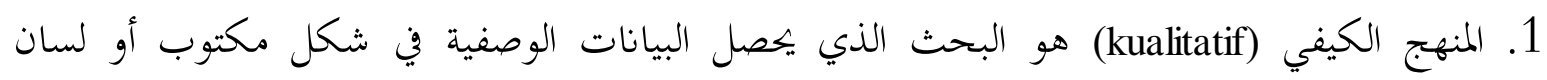
الإنسان وأفعله ليلاحظ. 2. المنهج الكمي (kuantitatif) هو الإجراء الذي يستعمل الأرقام في البحوث. 3

يختار ويستقدم الباحث في هذا البحث المنهج الكيفي، هو إجراءت البحث في إنتاج الوسائق الوصفية

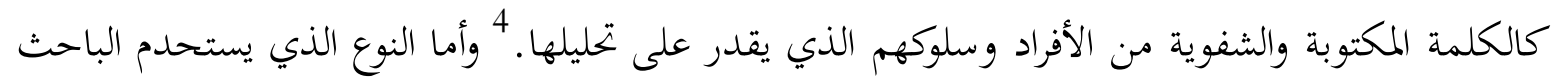
في هذا البحث هو الدراسة البلاغية.

بيانات البحث ومصادرها

\footnotetext{
${ }^{1}$ Hermawan W as ito،Pengantar Metode Penelitian (Jakarta: Gramedia Pustaka Utama ،1995) ‘hal 8.

${ }^{2}$ Lexy Moelong‘Metode penelitian kulitatif‘(Bandung: PT. Remaja Rosda Karya 2011) ‘hal: 4.

${ }^{3}$ Lexy Moelong،Metode penelitian kulitatif... chal 6

${ }^{4}$ Ridwan،Skala Pengukuran Variabe-variabel Penelitian ‘(Bandung: Alfabeta 2009) ‘hal: 5.
} 
البيانات هي المادة الخامة التى تطلب معالجة إضافية لإنتاج المعلومات أو الوصف، إما نوعية وإما كمية التى

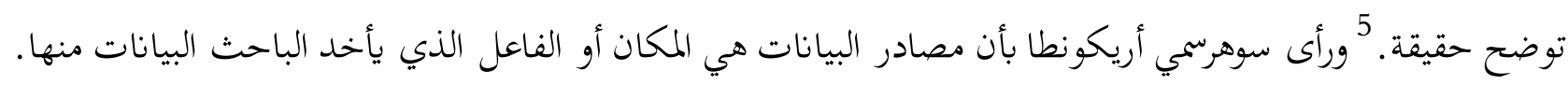

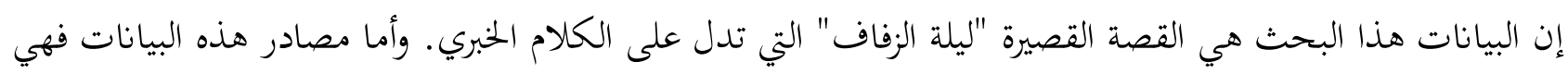
قصة القصيرة "ليلة الزفاف" لنجيب الكيلاني.

أدوات جمع البيانات

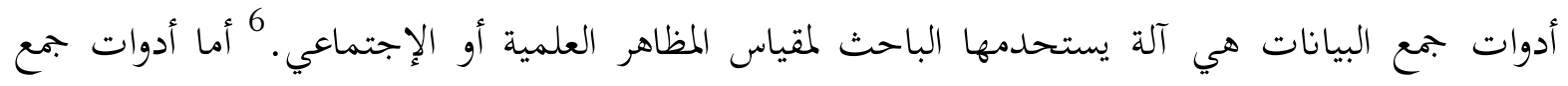

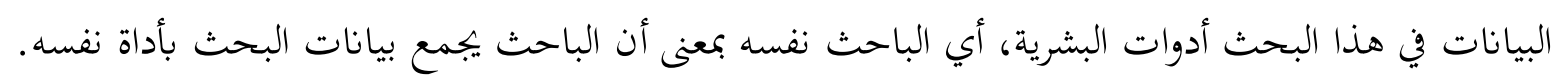

طريقة جمع البيانات

أما الطريقة المستحدمة في جمع بيانات هذا البحث، فهي طريقة الوسائق. وهي أن يقرأ الباحث في القصة

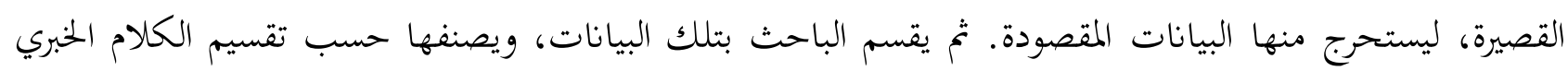

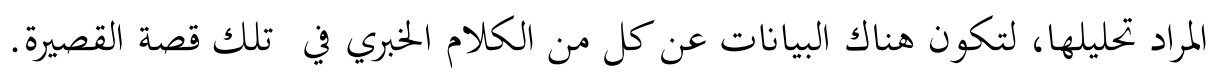

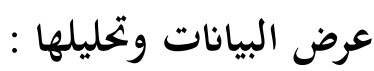
أنواع و أغراض الكلام الخبري فى قصة القصيرة "ليلة الزفاف" لنجيب الكيلالي

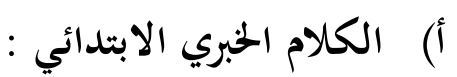
1 أكرهه من كل قلبى.

الكلمة تحتها الخط "أكرهه" هي من نوع الكلام الخبري الابتدائي لخلوها من أداة التوكيد، لأن المخاطب خالي الذهن من الحكم.

وأنا صغيرة. .وحلوة. .وأمقت النفاق والكذب.

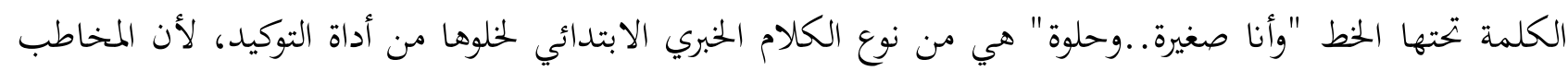

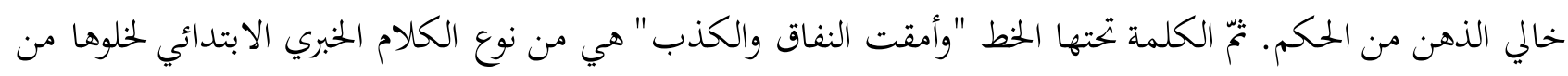

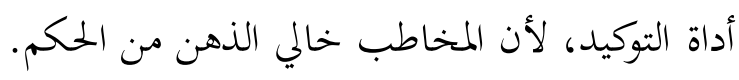

${ }^{5}$ Suhars imi Arikunto،Prosedur Penelitian Suatu Pendekatan Praktik ‘(Jakarta: Rineka Cipta 1991) hal 102.

${ }^{6}$ Sugiono ‘Metode Penelitian Kuantitatif ‘Kualitatif ‘dan R\&D،(Bandung: Alfabeta2010) ‘hal: 137.

$$
\text { 7ن نجيب الكيلاني, الكابوس (الصحوة: 2013), ص:1 }
$$


الكلمة تحتها الخط "الظلم أكبر الجرائم" هي من نوع الككام الخبري الابتدائي لخلوها من أداة التوكيد، لأن المخاطب

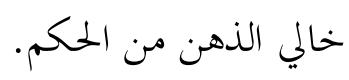

$$
\text { 4. }
$$

الكلمة تحتها الخطط "ومعمل تفريخ" هي من نوع الكلام الخبري الابتدائي لخلوها من أداة التوكيد، لأن المخاطب خالي الذهن من الحكم.

11 . 5

الكلمة تحتها الخط "هو فن السبعين من عمره" هي من نوع الكلام الخبري الابتدائي لخلوها من أداة التوكيد، لأن المخاطب خالي الذهن من الحكم. 6

الكلمة تحتها الخط "وأنا فن السابعة عشرة" هي من نوع الكلام الخبري الابتدائي لخلوها من أداة التوكيد، لأن المخاطب

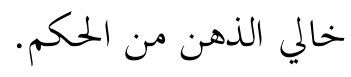
. 7 الكلمة تحتها الخط "هو زوجى" هي من نوع الككام الحببري الابتدائي لخلوها من أداة التوكيد، لأن المخاطب خالي الذهن من الحكم.

كلما تطلعت إلى عينيه، تذكر العلمة المعدنية الملساء الزائفة، وانبعثت في قلبى أنغام لحن جنائزى قديم سمعته

$$
\begin{aligned}
& \text { 9نجيب الكيلاني, الكابوس (الصحوة: 2013), ص:1 }
\end{aligned}
$$

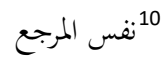

$$
\begin{aligned}
& \text { 11 10نس المرجع لمرجع } \\
& \text { 12 نفس المرجع المنع } \\
& \text { 13 نجيب الكيلاني, الكابوس (الصحوة: 2013), ص:1 } 1 \\
& \text { 14 نفس المرجع }
\end{aligned}
$$


الكلمة الأولى تحتها الخط "كلما تطلعت إلى عينيه، تذكر العلمة المعدنية الملساء الزائفة" هي من نوع الكلام الخبري

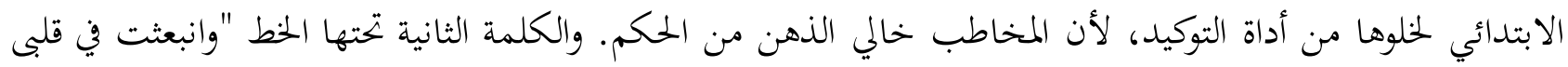

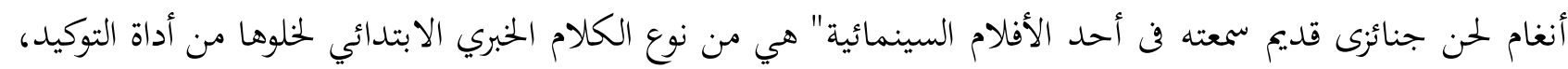
لأن المخاطب خالي الذهن من الحكم.

تجاعيد وجهه تذكرن بالمثل الشائع، غير أن دروب وجهه لا تقودن إلا التيه و الضياء. وعالم الجدب

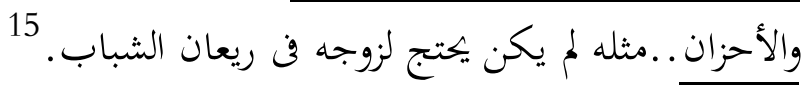

الكلمة الأولى تحتها الخط "تجاعيد وجهه تذكرنف بالمثل الشائع" هي من نوع الكلام الخبري الابتدائي لخلوها من أداة

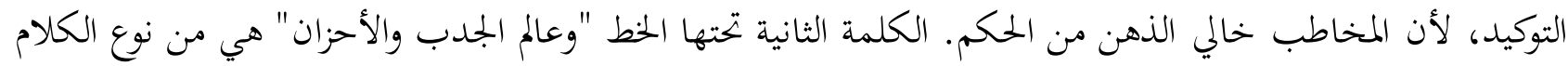

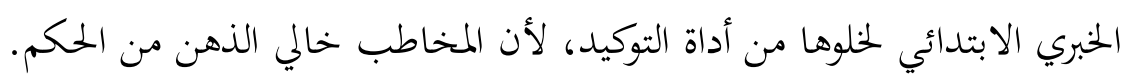

\section{0. الناس هنا لا يفرقون بين وظائف الأننى..كزوجة ..أو خدمة. .أو ممرضة. 16}

الكلمة تحتها الحط "الناس هنا لا يفرقون بين وظائف الأنثى..كزوجة..أو خدمة ..أو ممرضة" هي من نوع الكلام الحبري

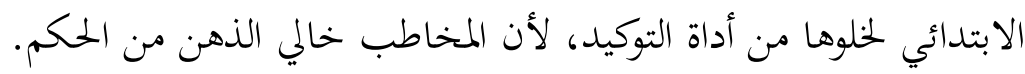

\section{1. الأنثى تستعمل في أى شيء.}

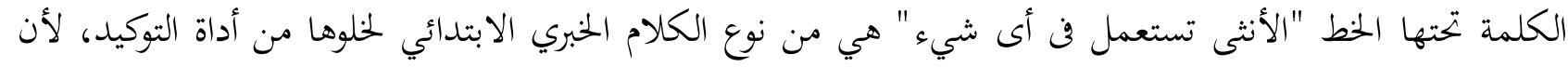

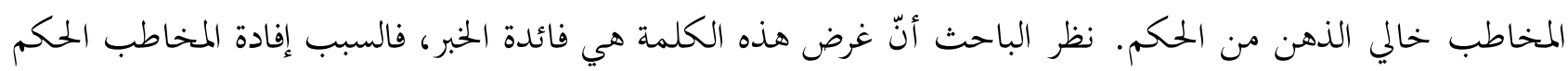
الذي تضمنته الجملة. وتلك الكلمة تدل على آناية نورة لحالتها أي تزويجها بمن لايردبه.

يانورة كى أقبلك) خطوت .ويلهث ..ويسعل..ولوّح بيده المرتعشة، ورأسه هى الأجرى كانت تر تعش، وقال: (اقتربي متّى

الكلمة الأولى تحتها الخط "جاءنى يعرج..ويلهث..ويسعل..ولوّح بيده المرتعشة" هي من نوع الكلام الخبري الابتدائي

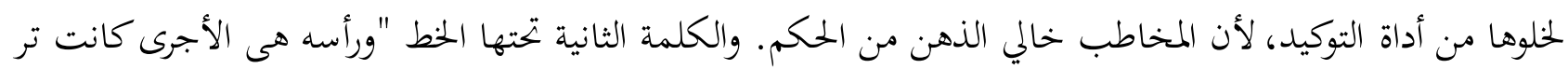
تعش" هي من نوع الكلام الخبري الابتدائي لخلوها من أداة التوكيد، لأن المخاطب خالي الذهن من الذهن من الحكم. والكلمة

$$
\begin{aligned}
& \text { 15 نفس المرجع } \\
& \text { 16 نجيب الكيالاني, الكابوس (الصحوة: 2013), ص:2 } \\
& \text { 17 نفس المرجع الميب النغي } \\
& \text { 18 }
\end{aligned}
$$


الثالثة تحتها الخط "وقال: (اقتربي منّى يانورة كى أقبلك) خطوت إليه" هي من نوع الكلام الخبري الابتدائي لخلوها من

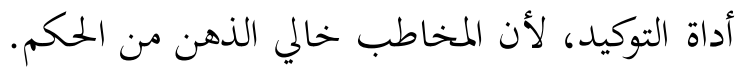

19 13. وغبت عن الوجود في رحلة إلى عالم النسيان الأسود المخيف كنت فريسة كابوس مرهق معطم للأعصاب. الكلمة تحتها الخط "وغبت عن الوجود في رحلة إلى عالم النسيان الأسود المخيف كنت فريسة كابوس مرهق محطم

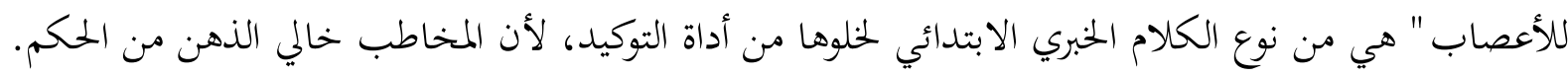

$$
\text { 14. جلسنا نتناول الطعام كان ضعيف البصر لدرجة كبيرة. }
$$

الكلمة تحتها الخط "جلسنا نتناول الطعام" هي من نوع الكلام الخبري الابتدائي لخلوها من أداة التوكيد، لأن المخاطب خالي الذهن من الحكم.

15. مأخد يتحسس الأطباق ليعرف ما أمامه من معكولات. الكلمة تحتها الخط "وأخد يتحسس الأطباق" هي من نوع الكلام الخببري الابتدائي لخلوها من أداة التوكيد، لأن

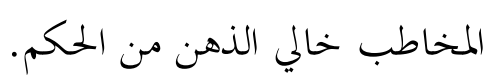

\section{6.}

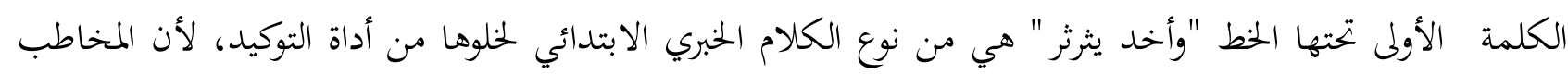

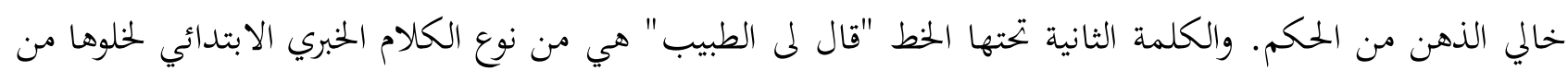

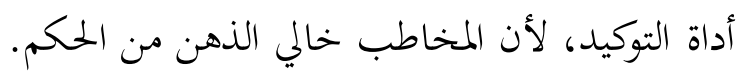

الشافى هو الله. . صحتى قوية كالحصان. .17

الكلمة تحتها الخط "الشاف هو الله" هي من نوع الكلام الخبري الابتدائي لخلوها من أداة التوكيد، لأن المخاطب خالي الذهن من الحكم.

رحم الله أيام زمان... كنت فارسا لا يشق له غبار ..حاربت.. .وقتلت. .18

$$
\begin{aligned}
& \text { 19 }{ }^{19} \\
& \text { 20 نفس المرجع } \\
& \text { 21 20نس المرجع المرجع } \\
& \text { 22 نجيب الكيلاني , الكابوس (الصحوة: 2013),ص:صنيع لمرجي } \\
& \text { نفنس المرجع الكيان }
\end{aligned}
$$


الكلمة الأولى تحتها الخط "رحم الله أيام زمان" هي من نوع الكلام الخبري الابتدائي لخلوها من أداة التوكيد، لأن

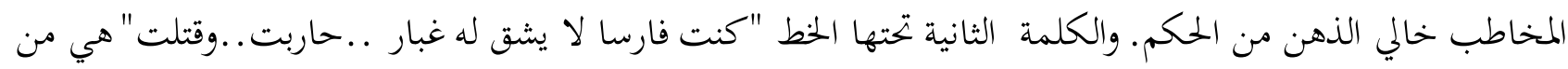

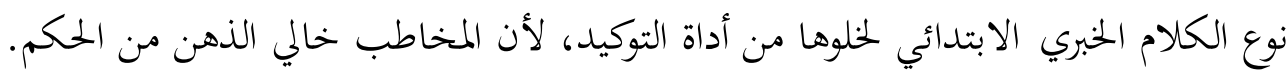

\section{9.}

الكلمة تحتها الخط "وتزوجت كثيرة" هي من نوع الكلام الخبري الابتدائي لخلوها من أداة التوكيد، لأن المخاطب خالي

$$
\text { الذهن من الحكم. } 20
$$

الكلمة تحتها الخط "الناس تعرف من أنا" هي من نوع الكلام الخبري الابتدائي لخلوها من أداة التوكيد، لأن المخاطب

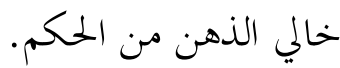

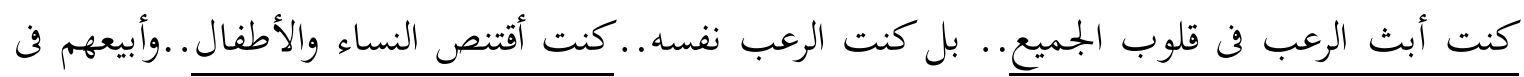

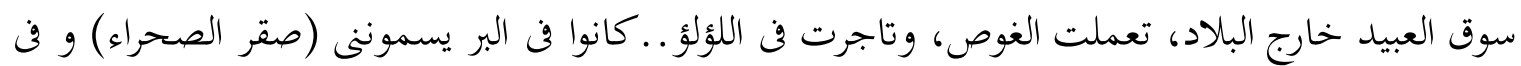

$$
27 .
$$

الكلمة الأولى تحتها الخط "كنت أبث الرعب فن قلوب الجميع" هي من نوع الكلام الخببري الابتدائي لخلوها من أداة

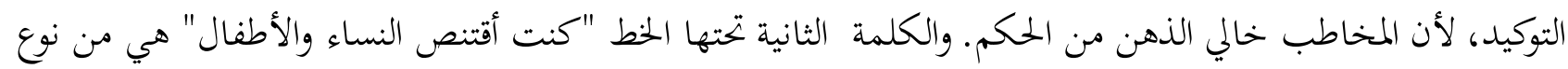

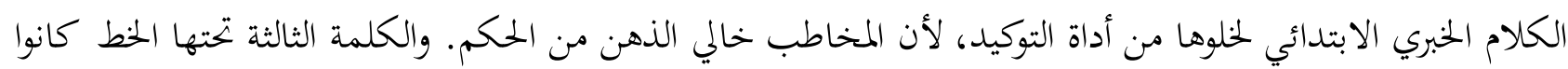

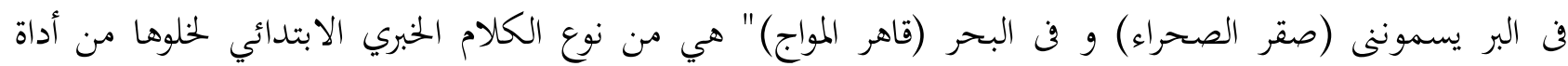

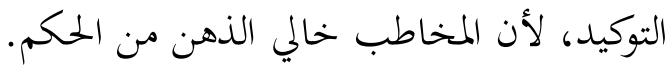

نظرة إلى جدغ النخلة المتاكل، وإلى جذوره الذابلة..وعلامات الفناء تدب فن كل أوصاله، وشعرت بموجة

الكلمة الأولى تحتها الخط "نظرة إلى جدغ النخلة المتاكل، وإلى جذوره الذابلة" هي من نوع الكلام الخبري الابتدائي

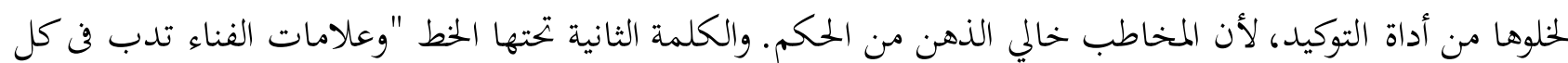

$$
\begin{aligned}
& \text { نفنس المرجع } \\
& \text { 25 نجيب الكيلاني, الكابوس (الصحوة: 2013), ص:3 } \\
& \text { 26 نفس المرجع } \\
& \text { 27 نفس المرجع المرجع } \\
& \text { 28:جيب الكيلاني, الكابوس (الصحوة: 2013), ص:3 }
\end{aligned}
$$


أوصاله" هي من نوع الكلام الخبري الابتدائي لخلوها من أداة التوكيد، لأن المخاطب خالي الذهن من الحكم. والكلمة

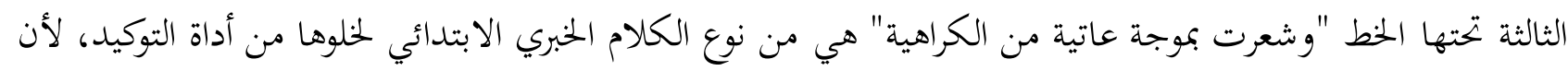

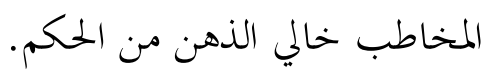

29

نظرت إلى طاقم الأسنان الصناعى وهو ينهس اللحم. .23

الكلمة تحتها الخط "نظرت إلى طاقم الأسنان الصناعى وهو ينهس اللحم" هي من نوع الكلام الخبري الابتدائي لخلوها

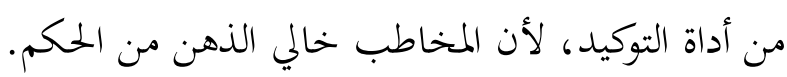

وتخصبة لحيته البيضاء،وتلويث أصابعه المرتجفة وبدالى شاربه ينتفض. .24

الكلمة الأولى تحتها الخط "وتخصبة لحيته البيضاء" هي من نوع الكلام الخبري الابتدائي لخلوها من أداة التوكيد، لأن

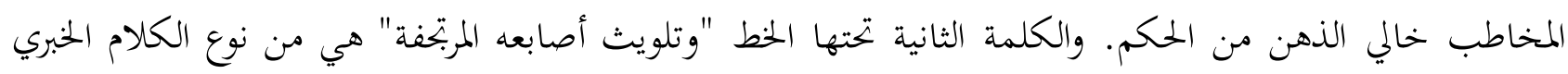

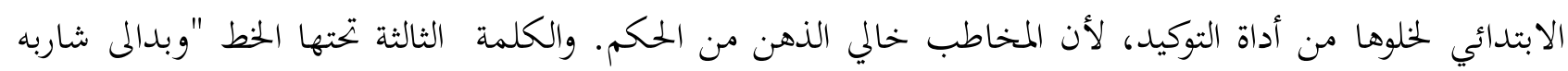

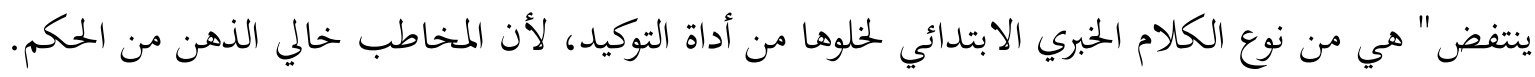

تنتصب عليه أدنا وحش مفترس، بل وبدالى أيضا أنه يعوى كو حش ضار أصابه داء الكلب، فجن جنونه

\section{فصرخت بأعلى صوتى طالبه النجدة.}

الكلمة تحتها الخط "فجن جنونه فصرخت بأعلى صوتى طالبه النجدة" هي من نوع الكلام الخبري الابتدائي لخلوها من

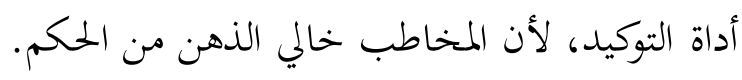

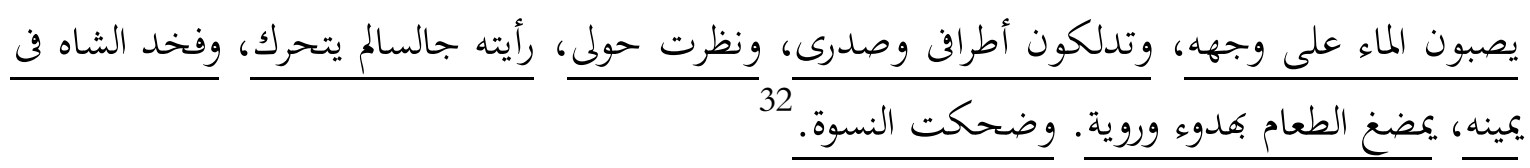

الكلمة الأولى تحتها الخط "يصبون الماء على وجهه" هي من نوع الكلام الخبري الابتدائي لخلوها من أداة التوكيد، لأن

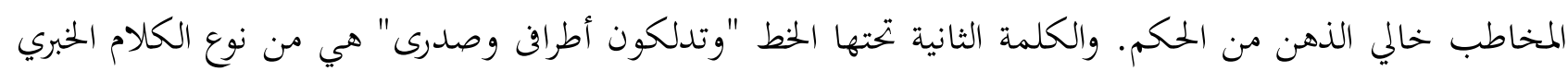

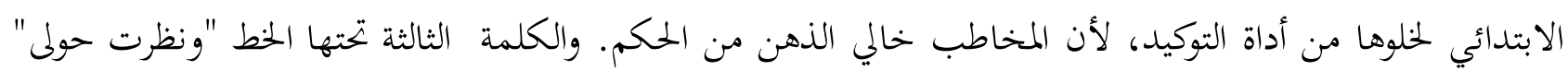

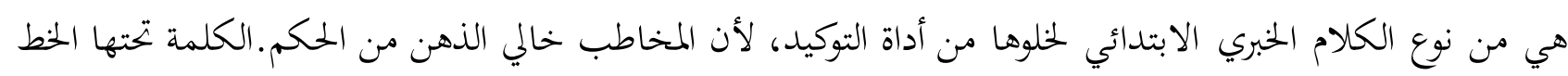

$$
\begin{aligned}
& \text { 29نجيب الكيلاني, الكابوس (الصحوة: 2013), ص:4 } \\
& \text { 30 } \\
& \text { 31 3نجيب الكيلاني, الكابوس (الصحوة: 2013), ص:4 }
\end{aligned}
$$

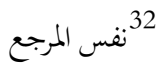


"رأيته جالسالم يتحرك" هي من نوع الكلام الخبري الابتدائي لخلوها من أداة التوكيد، لأن المخاطب خالي الذهن من

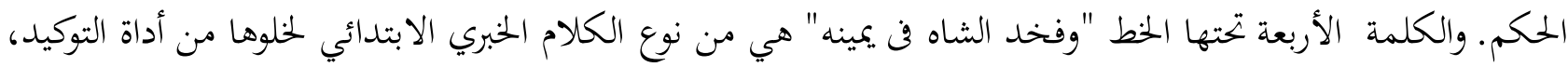

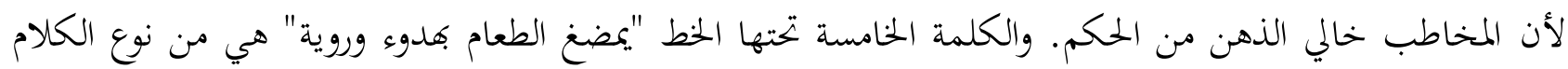

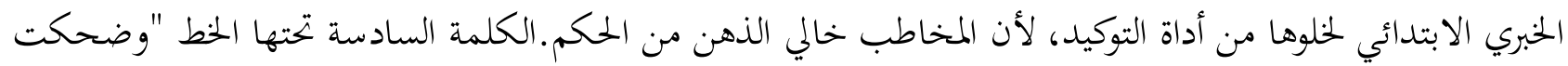

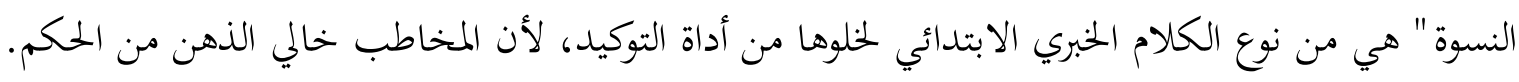

وخرجت النسوة، وعاد الصمت من جديد.

الكلمة تحتها الخط "وخرجت النسوة" هي من نوع الكلام الخبري الابتدائي لخلوها من أداة التوكيد، لأن المخاطب خالي

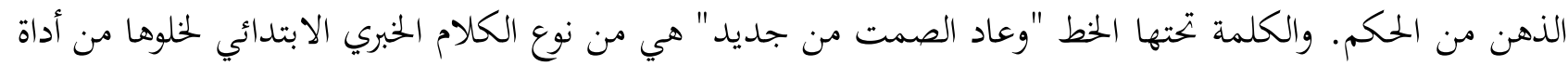
التوكيد، لأن المخاطب خالي الذهن من الحكم.

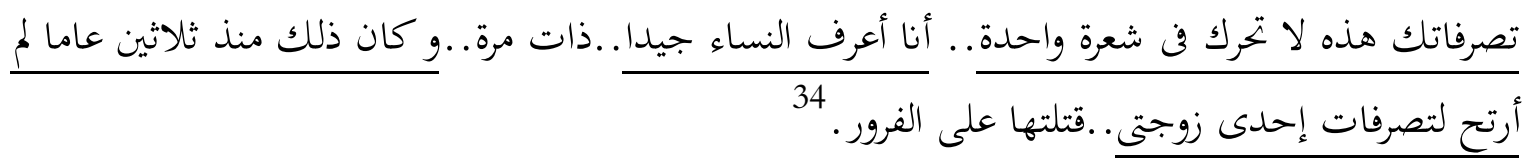

الكلمة تحتها الخط "تصرفاتك هذه لا تحرك في شعرة واحدة" هي من نوع الكلام الخبري الابتدائي لخلوها من أداة

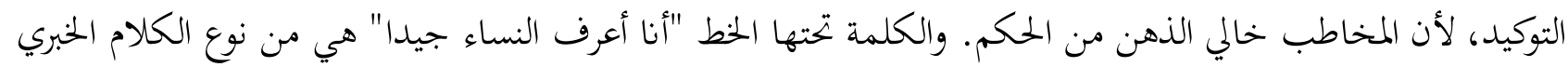

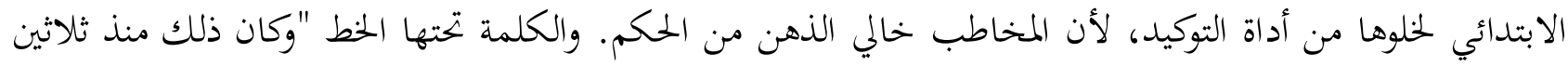

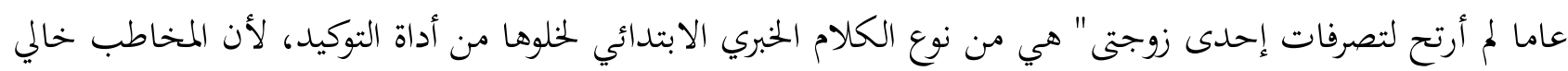
الذهن من الحكم.

$$
\text { ضحك ضحكة سمجة تبعث على الضيق والاشمئزاز وقال: (إنه رجل) } 35 .
$$

الكلمة تحتها الخط "ضحك ضحكة سمجة تبعث على الضيق والاشمئزاز" هي من نوع الكلام الخبري الابتدائي لخلوها

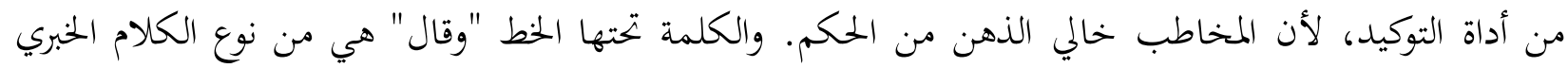

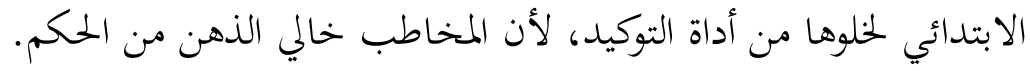

$$
\text { كانت هناك أسياء كثيرة، أردت أن أقولها له. }
$$

$$
\begin{aligned}
& \text { 33 }
\end{aligned}
$$

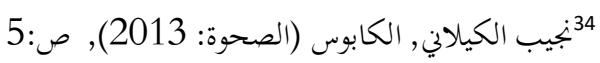

$$
\begin{aligned}
& \text { 35 } \\
& \text { 36نيب الكيلاني, الكابوس (الصحوة: 2013), ص:6 }
\end{aligned}
$$


الكلمة تحتها الخط "كانت هناك أسياء كثيرة" هي من نوع الكلام الخبري الابتدائي لخلوها من أداة التوكيد، لأن

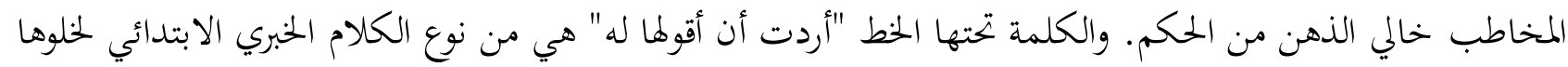

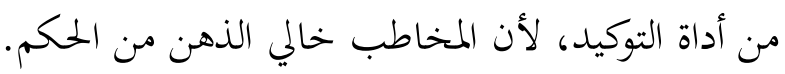

\section{31 31}

الكلمة تحتها الخط "فقد بدالى تافها لا وزن له" هي من نوع الكلام الخبري الابتدائي لخلوها من أداة التوكيد، لأن

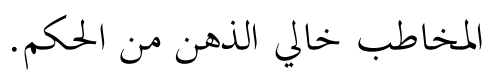

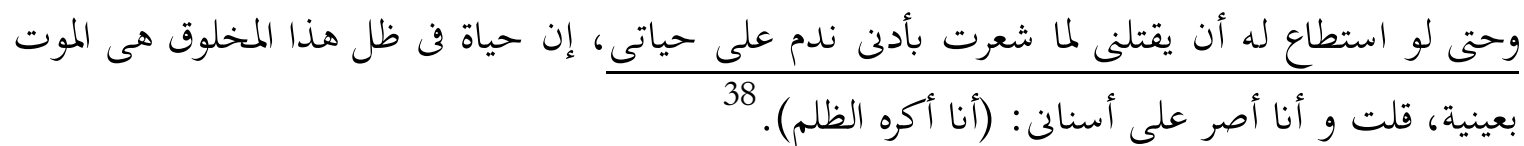

الكلمة تحتها الخطا "وحتى لو استطاع له أن يقتلنى لما شعرت بأدنى ندم على حياتى" هي من نوع الكلام الخبري

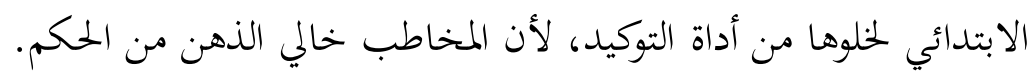

39 أنت ساذجة ..الظلم صناعة الأقوياء. .33

الكلمة تحتها الخط "أنت ساذجة . الظلم صناعة الأقوياء" هي من نوع الكلام الخبري الابتدائي لخلوها من أداة التوكيد، لأن المخاطب خالي الذهن من الحكم.

34. كل ما يطلب منك دون أن يوافق هواك فهو ظلم، لكنه فن نظرالآخر ضرورة و عدل. 40 الكلمة تحتها الخط "كل ما يطلب منك دون أن يوافق هواك فهو ظلم" هي من نوع الكلام الخبري الابتدائي لخلوها من

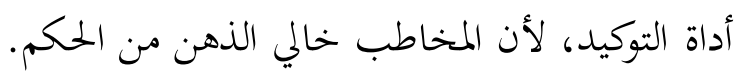
35. ومسح على لحيته البيضاء، وشارب الكث، ثم استطرد. الكلمة تحتها الخط "ومسح على لحيته البيضاء" هي من نوع الكلام الخبري الابتدائي لخلوها من أداة التوكيد، لأن

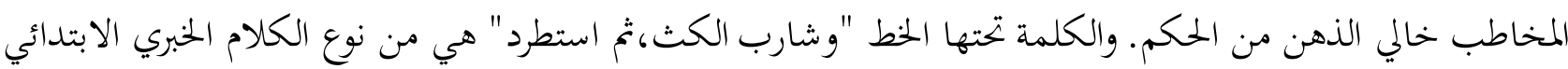

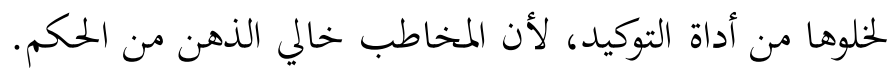

$$
\begin{aligned}
& \text { كنف } \\
& \text { 3is } \\
& \text { 39 } 39 \text { نغيب لكيالاني الكابوس (الصحوة: 2013), ص:6 }
\end{aligned}
$$

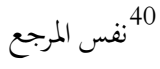

$$
\begin{aligned}
& \text { نفس المرجع لنغ المرجع }
\end{aligned}
$$


42

قلت في نفور : (تحدث عن أى شيء إلا الحق). لشد ما أكره كلماته، ونبرات صوته.

.36

الكلمة تحتها الخط "قلت فن نفور" هي من نوع الككلام الخببي الابتدائي لخلوها من أداة التوكيد، لأن المخاطب خالي الذهن من الحكم.والكلمة تحتها الخط "ونبرة صوته" هي من نوع الكلام الخبري الابتدائي لخلوها من أداة التوكيد، لأن المخاطب خالي الذهن من الحكم.

يخاطب بجتمعا اخر، وله منطق مضحك ومحنق.

.37

الكلمة تحتها الخط "يخاطب مجتمعا اخر "هي من نوع الكلام الخبري الابتدائي لخلوها من أداة التوكيد، لأن المخاطب خالي الذهن من الحكم. والكلمة تحتها الخط "وله منطق مضحك ومحنق" هي من نوع الكلام الخبري الابتدائي لخلوها من أداة التوكيد، لأن المخاطب خالي الذهن من الحكم.

38. ويريد أن يفرض سلطانه وقيمه على امتداد الدهر، وكل المثل الرفعية.

الكلمة تحتها الخط "ويريد أن يفرض سلطانه وقيمه على امتداد الدهر" هي من نوع الكلام الخبري الابتدائي لخلوها من أداة التوكيد، لأن المخاطب خالي الذهن من الحكم. والكلمة تحتها الخط "وكل المثل الرفعية" هي من نوع الكلام الخبري الابتدائي لخلوها من أداة التوكيد، لأن المخاطب خالي الذهن من الحكم.

هذا السلاح وحده - برغم تفاهته قد يقلم أظافرها، ويرده إلى الصواب.

.39

الكلمة تحتها الخط "هذا السلاح وحده" هي من نوع الكلام الخبري الابتدائي لخلوها من أداة التوكيد، لأن المخاطب خالي الذهن من الحكم. والكلمة تحتها الخط "قد يقلم أظافها" هي من نوع الكلام الخبري الابتدائي لخلوها من أداة التوكيد، لأن المخاطب خالي الذهن من الحكم. والكلمة تحتها الخط "ويرده إلى الصواب" هي من نوع الكلام الخبري

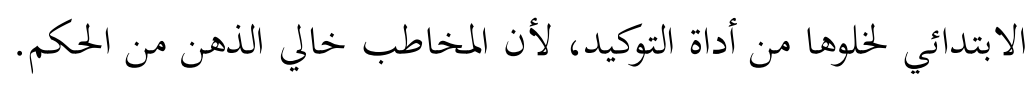

مشنقه). ارتجف شاربه، وأردأن يرد،لكنى لم أعطه فرصة واستطردت: (لوفكرت فن قتل زوجتى لك لساقوك إلى .40

$$
\begin{aligned}
& \text { 42 } 4 \text { نجيب الكيلاني, الكابوس (الصحوة: 2013), ص:6 } \\
& \text { 43 نفس المرجع } \\
& \text { 44 نفس المرجع المرجع } \\
& \text { 45 نجيب الكيلاني, الكابوس (الصحوة: 2013), ص:7 }
\end{aligned}
$$

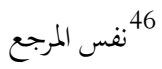


الكلمة تحتها الخط "ار بحف شاربه" هي من نوع الكلام الخبري الابتدائي لخلوها من أداة التوكيد، لأن المخاطب خالي الذهن من الحكم.

47

41. وأخذت أقهقهفى هسترية، وهو يجاهد ليحقق في تعبيرات وجهى، وصرخ كأسد جريح.

الكلمة تحتها الخط "وأخذت أقهقهفى هسترية" هي من نوع الكلام الخبري الابتدائي لخلوها من أداة التوكيد، لأن

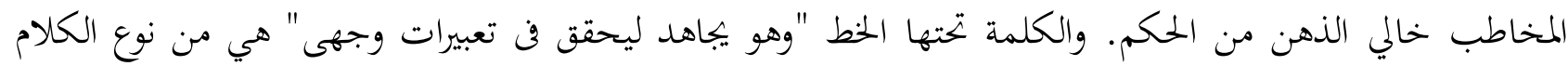

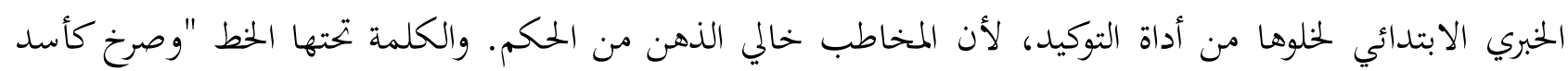

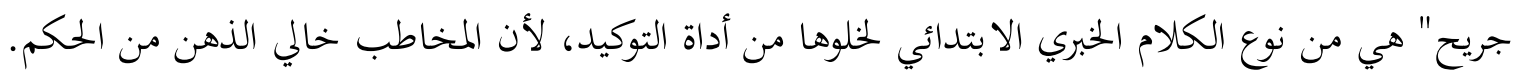
48.

الكلمة تحتها الخط "العصا وحدهاهي التى ستردك إلى صوابك" هي من نوع الكلام الخبري الابتدائي لخلوها من أداة

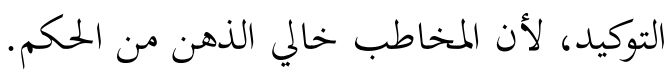

$$
\text { تحامل على نفسه، وبحث عن عصاه المعوجة التى يتكئ عليها. }
$$

الكلمة تحتها الخط "تحامل على نفسه" هي من نوع الكلام الخبري الابتدائي لخلوها من أداة التوكيد، لأن المخاطب خالي

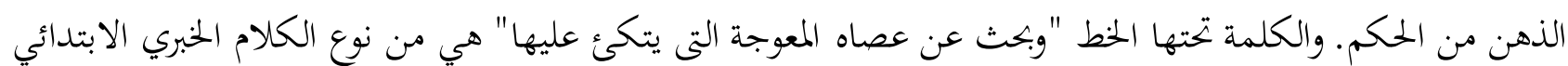

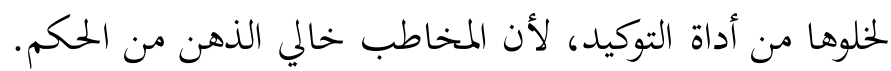
وأنا واقفه أرقب المشهد المخزن ضاحكة ساخرة. .44 الكلمة تحتها الخط "وأنا واقفه أرقب المشهد المخزن ضاحكة ساخرة" هي من نوع الكلام الخبري الابتدائي لخلوها من أداة التوكيد، لأن المخاطب خالي الذهن من الحكم.

ويرفع يده المرتعشة بالعصا محاولا أن ينزل بها على رأسى، ولكنى في لخظة قصيرة، وثبت كقطة صغيرة. 51

$$
\begin{aligned}
& 47 \text { 4جيب الكيلاني, الكابوس (الصحوة: 2013), ص:7 } \\
& \text { 48 نفس المرجع } \\
& \text { 49 نفس المرجع المرجع } \\
& \text { 50 5نيب الكيلاني, الكابوس (الصحوة: 2013), ص:7 } \\
& \text { 51 }
\end{aligned}
$$


الكلمة تحتها الخط "ويرفع يده المرتعشة بالعصا" هي من نوع الكلام الخبري الابتدائي لخلوها من أداة التوكيد، لأن

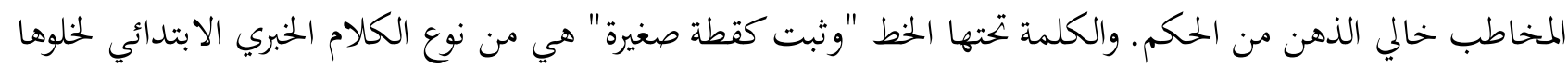

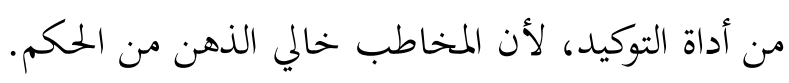

فهوت عصاه على الحائط، وكرر الهجوم عدة مرات، وفى كل مرة كنت أفلت من عصاه وأضحك. 52 .46 الكلمة تحتها الخطط "فهوت عصاه على الحائط" هي من نوع الكلام الخببري الابتدائي لخلوها من أداة التوكيد، لأن

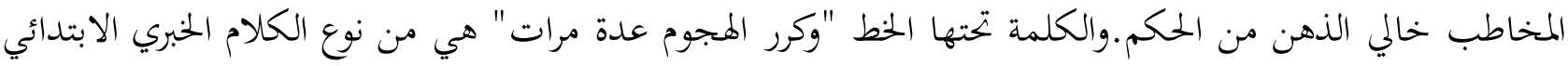

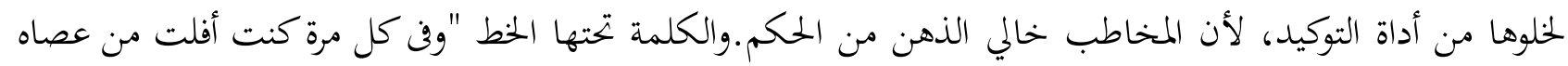

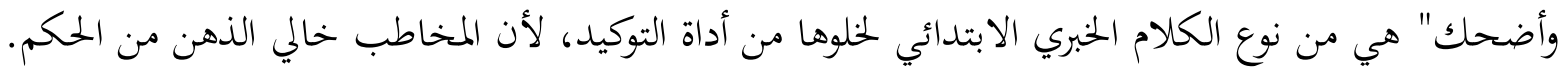
وحقى الضائع بأية وسيلة، فن عالم لا يؤمن بأن مرة إنسان.. كائن...له روح وقلب و أسواق قد تكون أقوى،

الكلمة تحتها الخطط "وحقى الضائع بأية وسيلة" هي من نوع الكلام الخبري الابتدائي لخلوها من أداة التوكيد، لأن

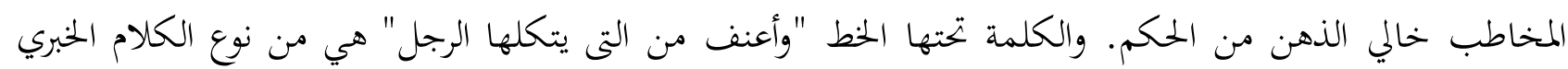

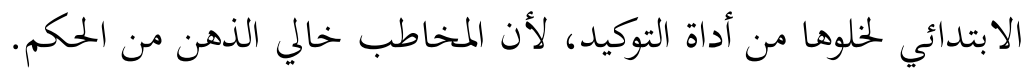

و ومقعدها، ورفع عصاه.

الكلمة تحتها الخط "وأخيرا حصرنى فن ركن من أركان الغرفة" هي من نوع الكلام الخبري الابتدائي لخلوها من أداة

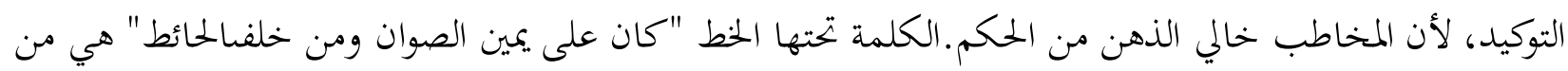

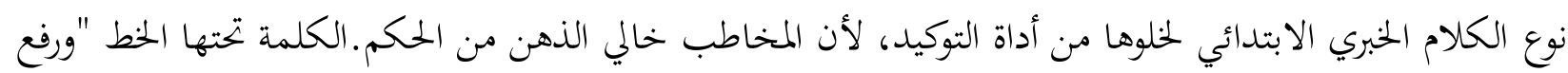

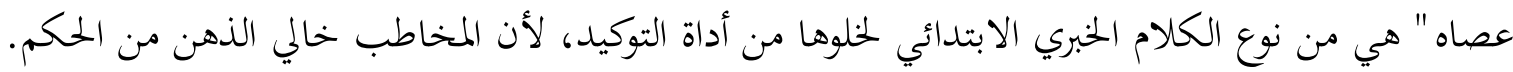

وقززفت بقوة، فار تطمت بصدره وبطنه. .فارتمى على ظهره متلا حق الأنفاس. 55

$$
\begin{aligned}
& \text { 52 }
\end{aligned}
$$

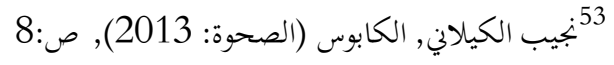

$$
\begin{aligned}
& \text { 50نس المرجع } \\
& \text { 55 نجيب الكيلاني, الكابوس (الصحوة: 2013), ص:8 }
\end{aligned}
$$


الكلمة تحتها الخطط "وقزفت بقوة" هي من نوع الكلام الخبري الابتدائي لخلوها من أداة التوكيد، لأن المخاطب خالي الذهن من الحكم.

وقفت جمده لحظة، ثم نظرت إلى وجهه الشاحب، وصدره الذى يعلو ويهبط فسرعة مخيفة، فصرخت بأعلى

.50

$$
\text { صوتى مرة أخرى طالب النجدة. }
$$

الكلمة تحتها الخط "وقفت جمده لحظة" هي من نوع الكلام الخبري الابتدائي لخلوها من أداة التوكيد، لأن المخاطب

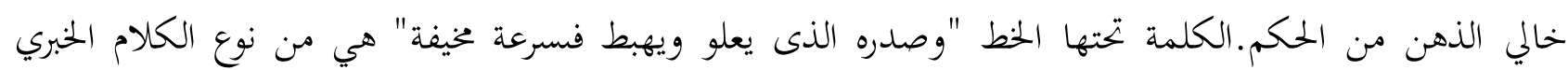

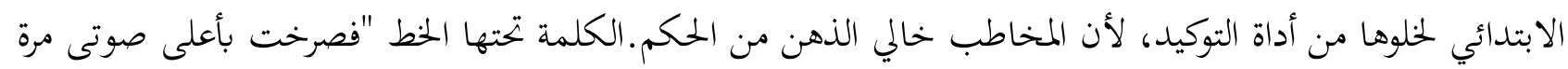

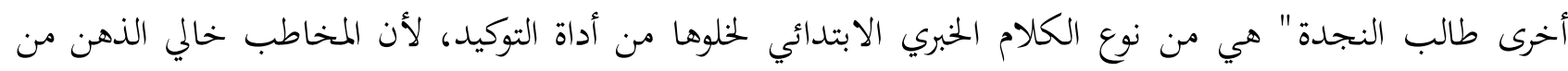

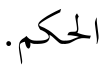

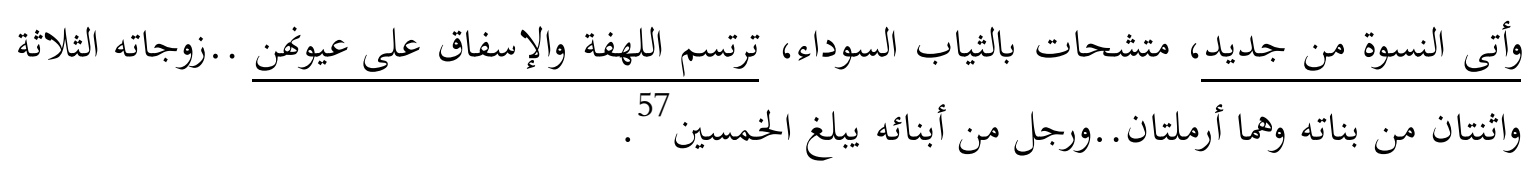

الكلمة تحتها الخط "وأتى النسوة من جديد" هي من نوع الكلام الخبري الابتدائي لخلوها من أداة التوكيد، لأن المخاطب تلحب

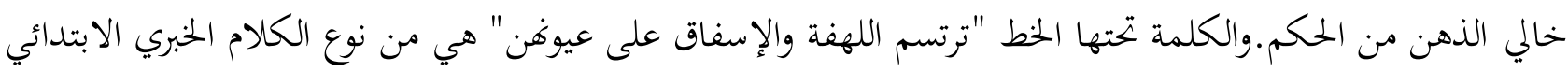

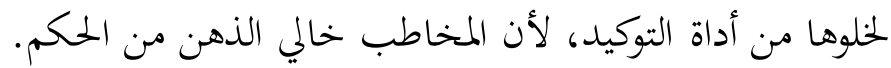

أشرت بأصبعى نهوأبيه دون أن أتكلم، كانت الدموع تسد حلقى،وتجرى فوق خدى.

.52

الكلمة تحتها الخط "أشرت بأصبعى نوأبيه دون أن أتكلم" هي من نوع الككلام الخبري الابتدائي لخلوها من أداة التوكيد،

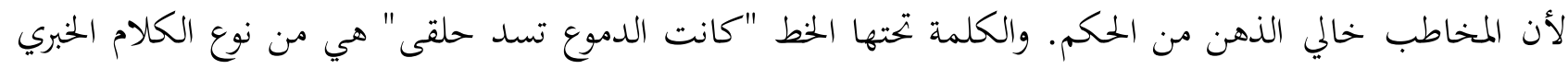

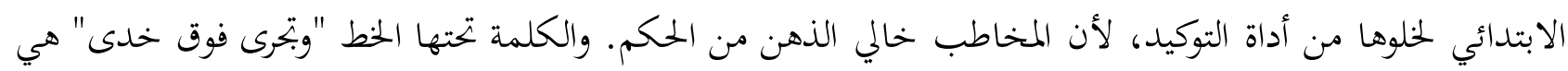

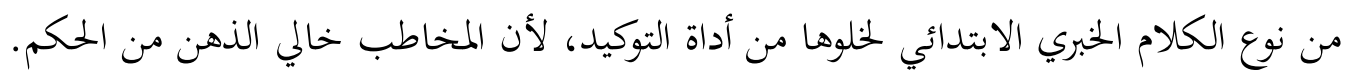
وأنا لا أكاد أصدق ما يحدث، لاشك أننى في حلم مخيف.

$$
\begin{aligned}
& \text { 56 نفس المرجع } \\
& \text { 57 } 57 \text { نجيب الكيلاني, الكابع الكنب (الصحوة: 2013), ص:8 } \\
& \text { 58 }
\end{aligned}
$$

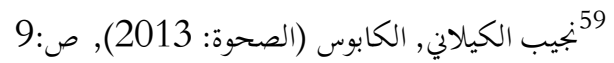


الكلمة تحتها الخط "وأنا لا أكاد أصدق ما يحدث" هي من نوع الكلام الحبري الابتدائي لخلوها من أداة التوكيد، لأن

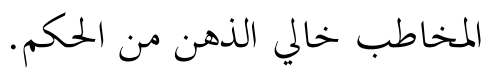

\section{4 . وانكب الجميع عليه، وتسللت أنا خارجة من باب الغرفة، ومسعت العجوز.}

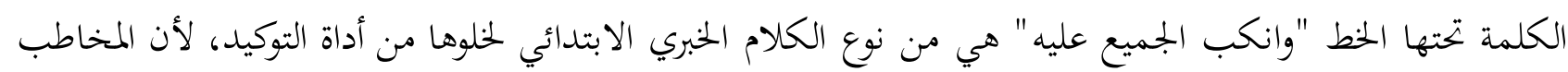

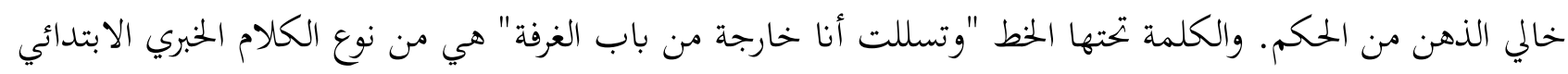

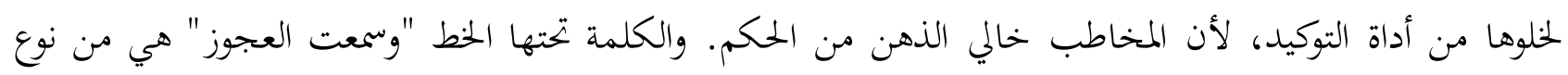

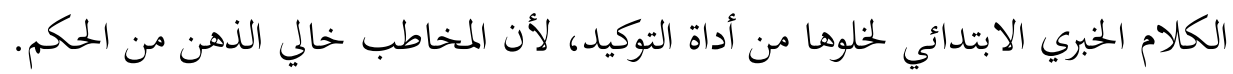

وجريت كطلفة صغيرة فن الشارع الصغير، حافية القدمين، وأنا لم أزل بثوب الزفاف. 61

.55

الكلمة تحتها الخط "وجريت كطلفة صغيرة فن الشارع الصغير" هي من نوع الكلام الخبري الابتدائي لخلوها من أداة

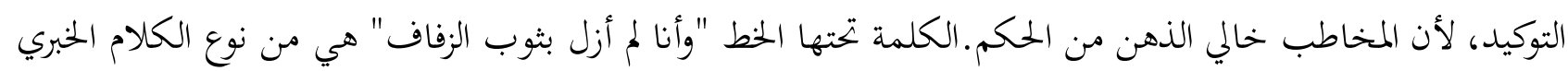
الابتدائي لخلوها من أداة التوكيد، لأن المخاطب من خالي لمالي الذهن من الحكم.

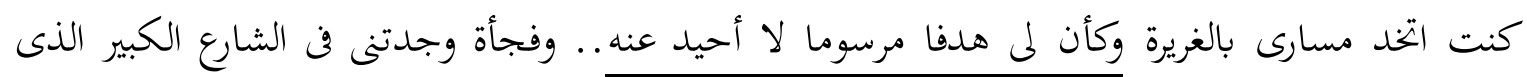
.56 62

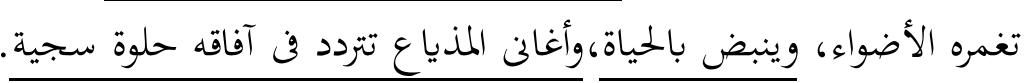

الكلمة تحتها الخط "وكأن لم هدفا مرسوما لا أحيد عنه" هي من نوع الكلام الخبري الابتدائي لخلوها من أداة التوكيد،

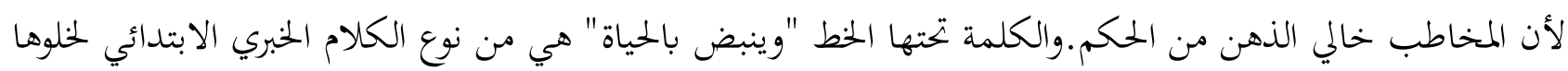

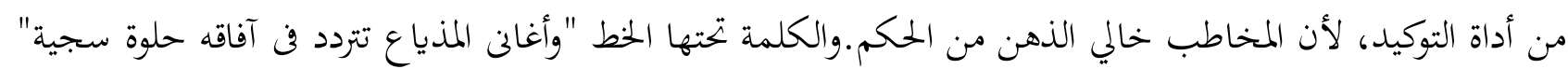

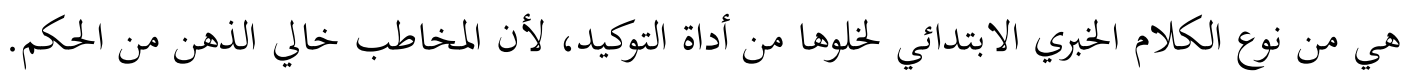

\subsection{7}

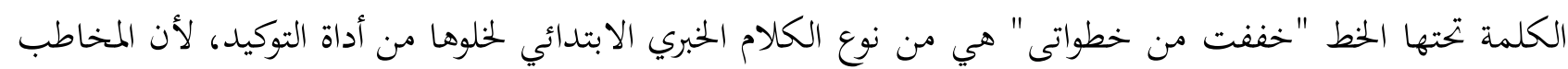

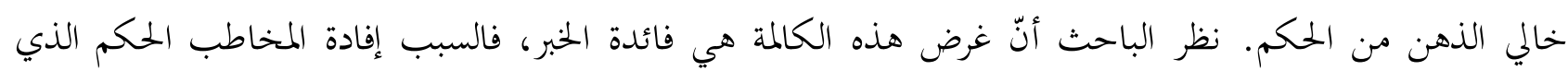
تضمنته الجملة. وتلك الكلمة تدل على آناية نورة لحالتها أي تزويجها بمن لايردبه.

$$
\begin{aligned}
& \text { 60 نفس المرجع } \\
& \text { ن21 } \\
& \text { 62 }
\end{aligned}
$$

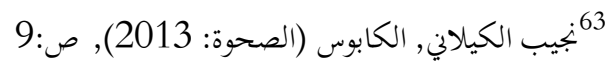


64 58

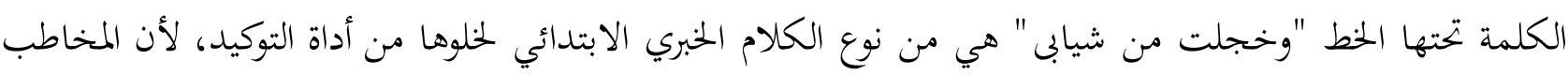

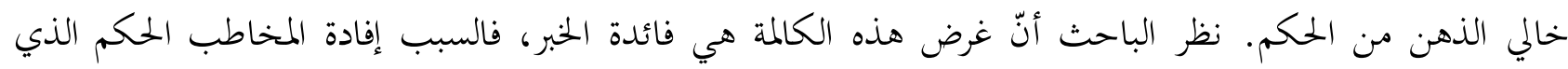
تضمنته الجملة. وتلك الكلمة تدل على آناية نورة لحالتها أي تزويجها بمن لايردبه.

$$
\text { 1) ب) الكلام الحبري الطلبي: }
$$

الكلمة تحتها الخط " وأكاد أجن" هي من نوع الكلام الخبري الطلبي لوجود أداة التوكيد، لأن المخاطب متردد في الحكم.

$$
\text { 2. أنا أكرهه... أكرهه من كل قلبى } 66 .
$$

الكلمة تحتها الخط "أنا أكرهه" هي من نوع الكلام الخبري الطلبي لوجود أداة التوكيد فيها وهي "التوكيد اللفظى أى أنا أكرهه"، لأن المخاطب متردد في الحكم وطالب أن يصل إلى اليقين في معرفته.

3. الحقيقة أنّى شعرت باشمعزاز بالغ، أثار فن نفسي الغسيان، كدت أدفعه بيدي فن غيظ. 67

الكلمة تحتها الخط "الحقيقة أننى شعرت باشعزاز بالغ" هي من نوع الكلام الحبري الطلبي لوجود أداة التوكيد فيها وهي "أنّ"، لأن المخاطب متردد في الحكم وطالب أن يصل إلى اليقين في معرفته.

4. فخيل إلى أنه لكم امرأة ضحية خطفها فى الزمن الغابر.

الكلمة تحتها الخط "فخيل إلى أنه لكم امرأة ضحية خطفها فن الزمن الغابر" هي من نوع الكلام الخبري الطبلي لوجود

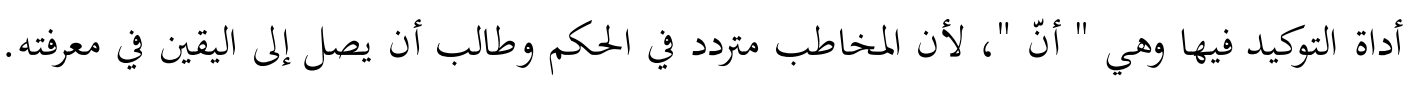

5. 5. وبدالى أن الدماء تثيل على أشدقه.

$$
\begin{aligned}
& \text { 64 نفس المرجع } \\
& \text { 65 نجيب الكيلاني, الكابوس (الصحوة: 2013), ص:1 } \\
& \text { 66 نفس المرجع } \\
& \text { 67 6جيب الكيلاني, الكابوس (الصحوة: 2013), ص:2013) }
\end{aligned}
$$

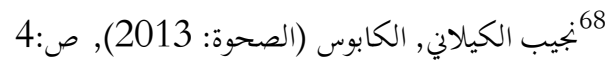

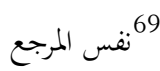


الكلمة تحتها الخط "وبدالى أن الدماء تثيل على أشدقه" هي من نوع الكلام الخببري الطبي لوجود أداة التوكيد فيها وهي "أنّ"، لأن المخاطب متردد في الحكم وطالب أن يصل إلى اليقين في معرفته. 6. بل وبدالى أيضا أنه يعوى كوحشضار أصابه داء الكلب.

الكلمة تحتها الخط "بل وبدالى أيضا أنه يعوى كوحشضار أصابه داء الكلب" هي من نوع الكلام الخبري الطلبي لوجود

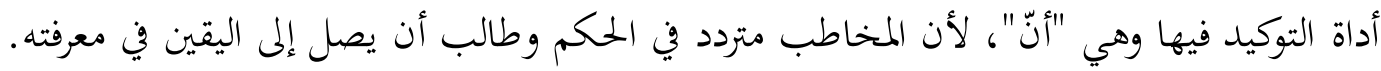

7. أنه حدثك عن بطولاته القديمة إنه يمزه بلا شك. 71

الكلمة تحتها الخط "أنه حدثك عن بطولاته القديمة إنه يمزه بلا شك" هي من نوع الكلام الخبري الطلبي لوجود أداة التوكيد فيها وهي "أنّ"، لأن المخاطب متردد في الحكم وطن وطالب أن يصل إلى اليقين في معرفته.

8. أما هو فقد حاول أن يضحك، لكن السعال سبقه. 72

الكلمة تحتها الخط "أما هو فقد حاول أن يضحك" هي من نوع الكلام الخبري الطبي لوجود أداة التوكيد فيها وهي "قد"، لأن المخاطب متردد في الحكم وطالب أن يصل إلى اليقين في معرفته.

$$
\text { 9. }
$$

الكلمة تحتها الخط "إنه رجل" هي من نوع الكلام الخبري الطلبي لوجود أداة التوكيد فيها وهي "إنّ"، لأن المخاطب متردد في الحكم وطالب أن يصل إلى اليقين في معرفته.

10.إنّ حياة في ظل هذا المخلوق هي الموت بعينية، قلت وأنال أصر على أسنانى.74.

الكلمة تحتها الخطا "إنّ حياة في ظل هذا المخلوق هي الموت بعينية" هي من نوع الكلام الخبري الطلبي لوجود أداة

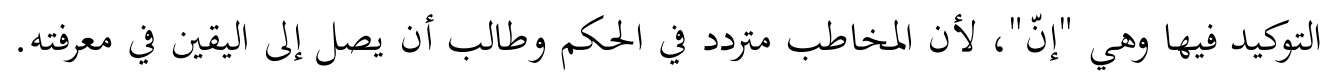

11. أنا أكره الظلم.

$$
\begin{aligned}
& \text { 70 } \\
& \text { 71 نجيب الكيلاني, الكابوس (الصحوة: 2013), ص:4 } \\
& \text { نفس المرجع }
\end{aligned}
$$

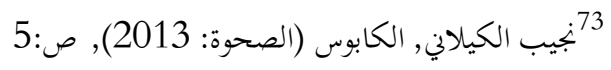

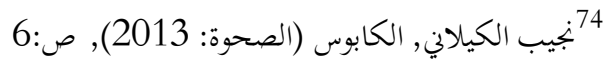

$$
\begin{aligned}
& \text { 75 نجيب الكيلاني, الكابوس (الصحوة: 2013), ص:6 الكحوة }
\end{aligned}
$$




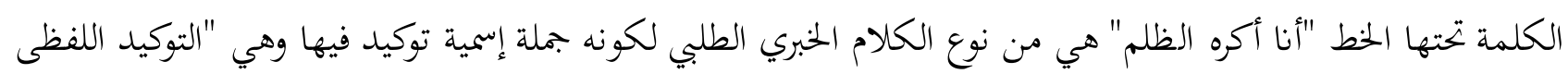
أى أنا أكره"، لأن المخاطب متردد في الحكم وطالب أن يصل إلى اليقين في معرفته. 12. أنت تعتقدين أنّ زواجك منى ظلم. 76

الكلمة تحتها الخط "أنت تعتقدين أنّ زواجك منى ظلم" هي من نوع الكلام الخبري الطبلي لوجود أداة التوكيد فيها وهي

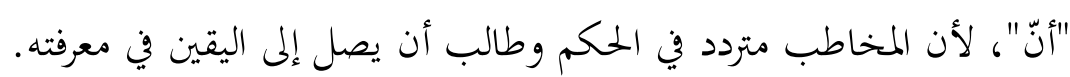

13. وملامح وجهه وأشعر أنّ بينى وبينه عصورا سحيقة. 77

الكلمة تحتها الخط "وملامح وجهه وأشعر أنّ بينى وبينه عصورا سحيقة" هي من نوع الكلام الخبري الطبي لوجود أداة

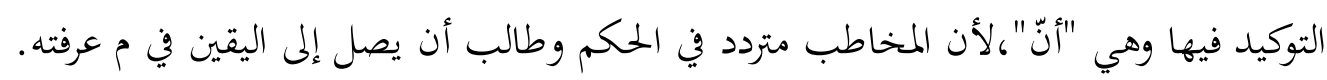

14. قلت وأنا أضحك في خلاعة مصطنعة. 78

الكلمة تحتها الخط "قلت وأنا أضحك في خلاعة مصطنعة" هي من نوع الكلام الخبري الطلبي لوجود أداة التوكيد فيها

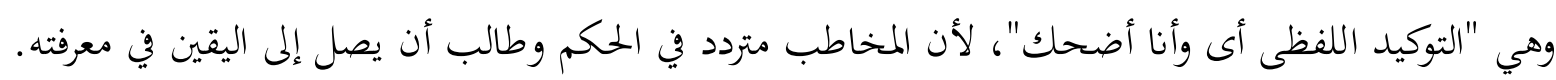

$$
\text { 15. إنّى لكذلك، لكنى أحتقر الزيف، وأمقت الظلم. } 79
$$

الكلمة تحتها الخط "إنىى لكذلك" هي من نوع الكلام الحبري الطلبي لوجود أداة التوكيد فيها وهي "إنّ"، لأن المخاطب متردد في الحكم وطالب أن يصل إلى اليقين في معرفته.

$$
\text { 16. كنت أتصرف بلا وعى يد فعنى إلى ذلك جنون ايأس، أوحرقة الظلم. } 80
$$

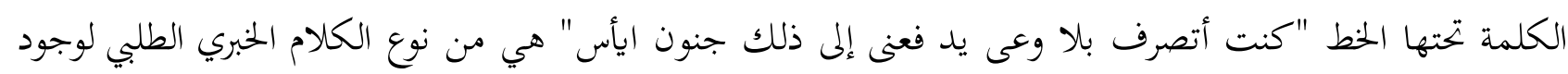

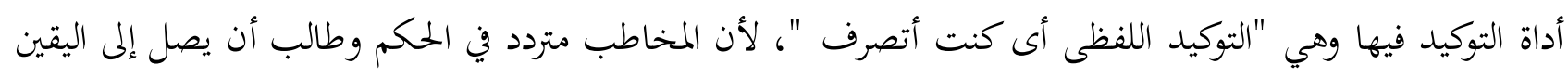
في معرفته.

17. كنت أريد أن أنفث عن تمودى وغضبى وشورتى. 81

$$
\begin{aligned}
& \text { 76 نفس المرجع } \\
& \text { 77 } \\
& \text { 78 } \\
& \text { 79 نجيب الكيلاني, الكابوس (الصحوة: 2013), ص:7 الكائرة }
\end{aligned}
$$

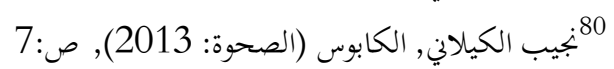


الكلمة تحتها الخط "كنت أريد أن أنفث عن تمودى وغضبى وشورتى" هي من نوع الكلام الخبري الطلبي لكونه جملة

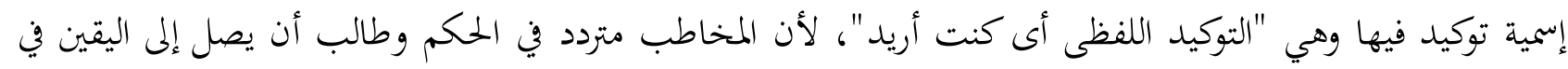

\section{8. وأنا أندس في أحصان الظلام البارد الوادع.82}

الكلمة تحتها الخط "وأنا أندس في أحصان الظلام البارد الوادع" هي من نوع الكلام الخبري الطلبي لكونه جملة إسمية توكيد فيها وهي "التوكيد اللفظى أنأنا أندس"، لأن المخاطب متردد في الطحان الطحم وطالب أنسا أن يصل إلى اليقين في معرفته.

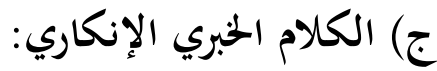
83

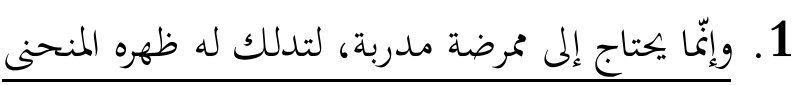
الكلمة تحتها الخط "وإنّا يحتاج إلى ممرضة مدربة، لتدلك له ظهره المنحن" هي من نوع الكلام الحبري الإنكاري لوجود

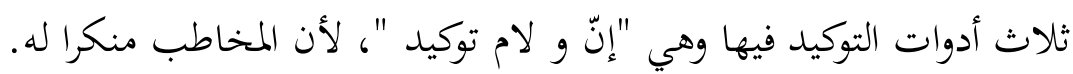

84

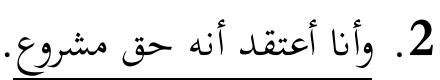

الكلمة تحتها الخط "وأنا أعتقد أنه حق مشروع" هي من نوع الكلام الخبري الإنكاري لوجود ثلاث أدوات التوكيد فيها

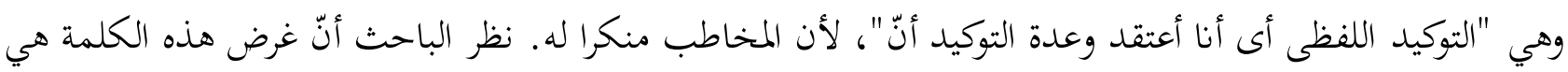

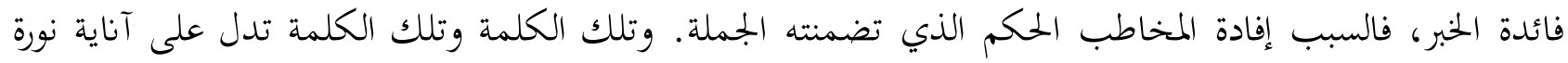
لحالتها أي تزويجها بمن لايردبه.

3. لكنى كنت أشعر أننى قضيت فن الكهف مائه عام برغم أها لم تكن سوى ساعات قليلة. 85

الكلمة تحتها الخط "لكنى كنت أشعر أننى قضيت فن الكهف مائه عام برغم أها لم تكن سوى ساعات قليلة" هي من الخها

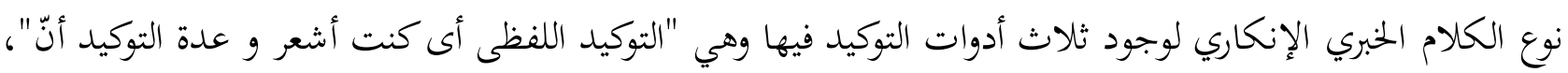

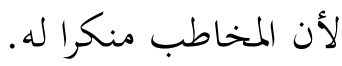

أغراض الكلام الحخبي في قصة القصيرة "ليلة الزفاف" لنجيب الكيلاني:

$$
\begin{aligned}
& \text { 81 } \\
& \text { 82 8جيب الكيلاني, الكابوس (الصحوة: 2013), ص:9 }
\end{aligned}
$$

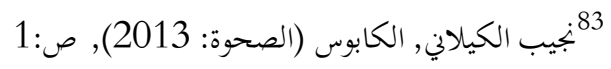

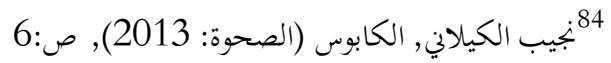

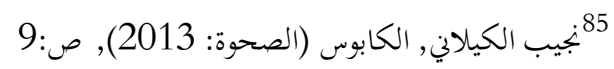


فالآن سيعرض الباحث عن فواعد الكلام الخبري قصة القصيرة "ليلة الزفاف" لنجيب الكيلاني، فيما يلى:

$$
\text { 1 أكرهه من كل قلبئدة الخبر. } 86
$$

نظر الباحث أنّ غرض هذه الكلمة هي فائدة الحخبر، فالسبب إفادة المخاطب الحكم الذي تضمنته الجملة. وتلك الكلمة تدل على آناية نورة لحالتها أي تزويجها بمن لايردبه

2) مأنا صغيرة. ..وحلوة .. وأمقت النفاق والكذب.

نظر الباحث أنّ غرض هذه الكلمة هي فائدة الخبر، فالسبب إفادة المخاطب الحكم الذي تضمنته الجملة. وتلك الكلمة تدل على آناية نورة لحالتها أي تزويجها بمن لايردبه.

$$
\text { 3) ولأكد أجن حينما أرى إنسانا-أو حتى حيوانا. } 88
$$

نظر الباحث أنّ غرض هذه الكلمة هي فائدة الخبر، فالسبب إفادة المخاطب الحلكم الذي تضمنته الجملة. وتلك الكلمة تدل على آناية نورة لحالتها أي تزويجها بمن لايردبه.

$$
\text { 4) (4 الظلم أكبر الجرائم. }
$$

نظر الباحث أنّ غرض هذه الكلمة هي فائدة الخبر، فالسبب إفادة المخاطب الحكم الذي تضمنته الجملة. وتلك الكلمة تدل على آناية نورة لحالتها أي تزويجها بمن لايردبه. 5) ومعمل تفريخ لشتى ألوان الفساد.

نظر الباحث أنّ غرض هذه الكلمة هي فائدة الخبر، فالسبب إفادة المخاطب الحكم الذي تضمنته الجملة. وتلك الكلمة تدل على آناية نورة لحالتها أي تزويجها بمن لايردبه.

$$
\text { هو في السبعين من عمره. وأنا في السابعة عشرة. } 91
$$

$$
\begin{aligned}
& \text { 86 نجيب الكيلاني, الكابوس (الصحوة: 2013), ص:1 } \\
& \text { 87 } \\
& \text { 88نجيب الكيلاني, الكابوس (الصحوة: 2013), ص:1 } 1 \\
& \text { 89 -نفس المرجع }
\end{aligned}
$$

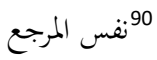

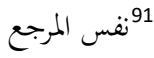


نظر الباحث أنّ غرض هذه الكلمة هي فائدة الخبر، فالسبب إفادة المخاطب الحكم الذي تضمنته الجملة. وتلك الكلمة تدل على آناية نورة لحالتها أي تزويجها بمن لايردبه.

نظر الباحث أنّ غرض هذه الكلمة هي فائدة الحبر، فالسبب إفادة المخاطب الحكم الذي تضمنته الجملة. وتلك الكلمة

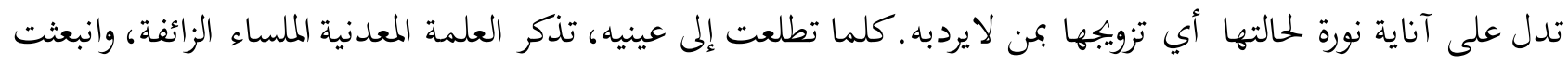

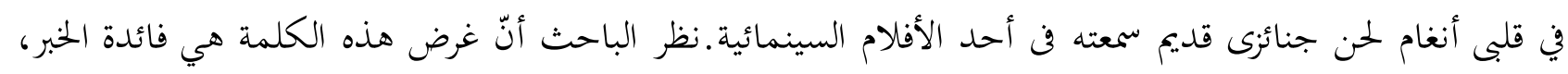
فالسبب إفادة المخاطب الحكم الذي تضمنته الجملة. وتلك الكلمة تدل على آلى آناية نورة لحالتها أي تزويجها بمن لايردبه. تجاعيد وجهه تذكرنى بالمثل الشائع، غير أن دروب وجهه لا تقودن إلا التيه والضياء. وعالم الجدب والأحزان ..مثله لم يكن يحتج لزوجه في ريعان الشباب. 93

نظر الباحث أنّ غرض هذه الكلمة هي فائدة الخبر، فالسبب إفادة المخاطب الحكم الذي تضمنته الجملة. وتلك الكلمة تدل على آناية نورة لحالتها أي تزويجها بمن لايردبه.

$$
\text { الناس هنا لا يفرقون بين وظائف الأنثى..كزوجة. .أو خدمة. .أو ممرضة. } 94
$$

نظر الباحث أنّ غرض هذه الكلمة هي فائدة الحبر، فالسبب إفادة المخاطب الحكم الذي تضمنته الجملة. وتلك الكلمة تدل على آناية نورة لحالتها أي تزويجها بمن لايردبه.

$$
\text { الأنثى تستعمل فن أى شيء. }
$$

نظر الباحث أنّ غرض هذه الكلمة هي فائدة الحبر، فالسبب إفادة المخاطب الحكم الذي تضمنته الجملة. وتلك الكلمة تدل على آناية نورة لحالتها أي تزويجها بمن لايردبه.

$$
\begin{aligned}
& \text { 2. لازم فائدة الحبر } \\
& \text { الشافى هو الله. . صحتى قوية كالحصان. } 96
\end{aligned}
$$

نظر الباحث أنّ غرض هذه الكلمة هي لازم فائدة، فالسبب إفادة المخطب أنّ المتكل عالم أيضا.

$$
\begin{aligned}
& \text { 92 92 } \\
& \text { 93 نفس المرجع } \\
& \text { 94 9جيب الكيلاني, الكابوس (الصحوة: 2013), ص:2013) } \\
& \text { 95 }
\end{aligned}
$$

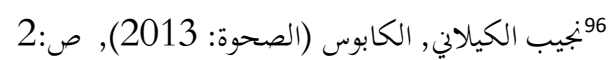


الإختام:

بعد أن بحث الباحث هذا البحث يعنى الكلام الخبري في قصة القصيرة "ليلة الزفاف" لنجيب الكيلاني، ففي هذا الفصل

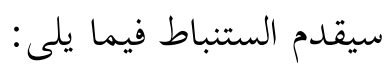
الكلام الخبري في قصة القصيرة "ليلة الزفاف" لنجيب الكيلاني ثلاثة أنواع، وهي: 1. الكلام الخبري الابتدائي، وهو أن يكون خالى الذهن من أداوت التوكيد، وعدده 58 نوعا.

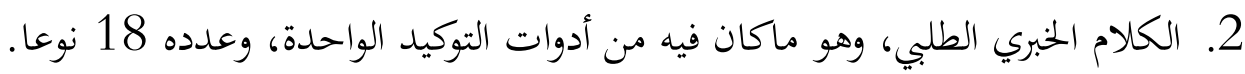

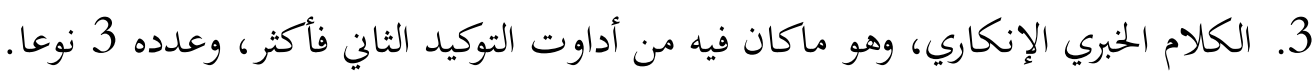
أغراض الكلام الخبري فيقصة القصيرة "ليلة الزفاف" لنجيب الكيلاني غرضان:

1. فائدة الخبر هي إفادة المخطاب الحكم الذي تضمنته الجملة، وجد الباحث في قصة القصيرة "ليلة الزفاف" لنجيب الكيلاني 10 فائدة الخبر.

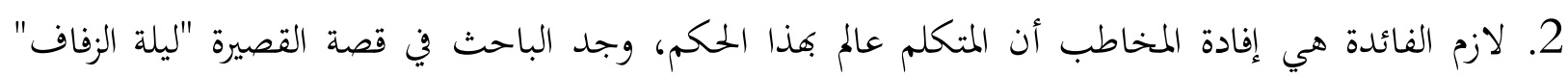
لنجيب الكيلاني 1 لازم الفائدة.

الجارم، على ومصطفي أمين. مجهول السنة. البلاغة الواضحة، بجهول المدينة.

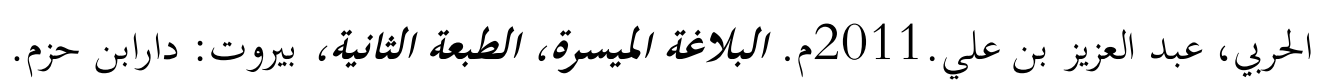
القطان، مناع. نجهول السنة. مباحث في علوم القرآن، القاهرة. مكتبة وهبة. القيلة، عبده عبد العزيز. 1992 م. البلاغة الإصطلاحة، الطبعة الثالثة، القاهرة: دار الفكر العربى.

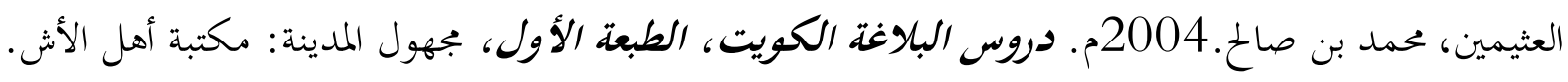

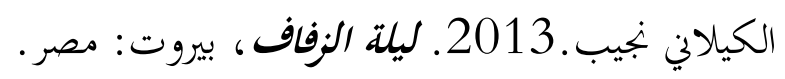

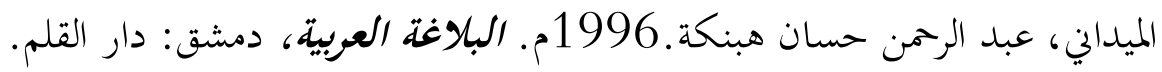
الهاشمي، السيد أحمد.1999 م. جواهر البلاغة، مكتبة العصرية. بيروت: مجهول المدينة. أمين،على الجارم ومصطفى.1961م. البلاغة الواضحة، الطبعة الخامسة عشرة، سورابايا: توكو كيتاب المداية.

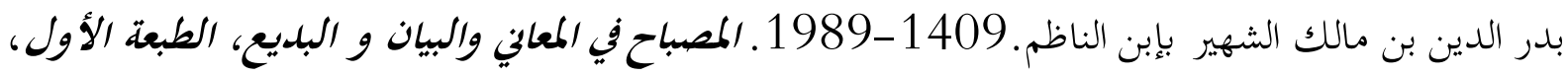
مجهول المدينة. 


$$
\begin{aligned}
& \text { رابيت، الهاشمي.2017. الجوهر المكنون، الطبعة الأول، جربون: بجهول المدينة. } \\
& \text { عاشورظ، الطاهر محمد بن.بجهول السنة. موجز الباغة،المجليد الأول، بيروت: دار الكتاب العلمية. } \\
& \text { فراويطا، إيدي. 2010م. جوهر المكنون، فنورجو: دار الهدي فريس. }
\end{aligned}
$$

Clancey, W.J. "Communication, Simulation, and In-telligent Agents: Implications of Personal Arikuntor Suharsimi, 1991. Prosedur Penelitian Suatu Pendekatan Praktik. Jakarta: Rineka Cipta.

Moelong, Lexy.2011. Metode penelitian kulitatif, Bandung: PT. Remaja Rosda Karya.

Ridwan, 2009. Skala Pengukuran Variabe-variabel Penelitian, Bandung: Alfabeta.

Sugiono, 2010. Metode Penelitian Kuantitatif, Kualitatif dan R\&D, (Bandung: Alfabeta.

Wasito, Hermawan.1995. Pengantar Metode Penelitian, Jakarta: Gramedia Pustaka Utama 